\title{
Retraction: Ectopic expression of the histone methyltransferase Ezh2 in haematopoietic stem cells causes myeloproliferative disease
}

\author{
A. Herrera-Merchan, L. Arranz, J.M. Ligos, A. de Molina, O. Dominguez \& S. Gonzalez
}

Nature Communications 3:623 doi: 10.1038/ncomms1623 (2012); Published 10 Jan 2012; Updated 7 Mar 2017

We the authors are retracting this Article as it has come to our attention that there has been inappropriate duplication of images between different figures of the published paper, and between figures in the paper and those in work previously published by the corresponding author (Arranz et al., 2012, Herrera-Merchan et al., 2010). The figure panels affected are Figs 2c, 3d, 4e, 5g, 7a, Supplementary Figs $2 \mathrm{~b}, 3 \mathrm{~b}$ and $5 \mathrm{~d}$. The corresponding author, $\mathrm{S}$. Gonzalez, was unable to supply a complete set of raw data on which the Article is based. The Centro Nacional de Investigaciones Cardiovasculares Carlos III and the first author A. Herrera-Merchan, together with the co-authors L. Arranz, J.M. Ligos, A. de Molina and O. Dominguez, agree with retraction of the Article.

Arranz, L. et al. Bmil is critical to prevent Ikaros-mediated lymphoid priming in hematopoietic stem cells. Cell Cycle 11, 65-78 (2012).

Herrera-Merchan, A. et al. miR-33-mediated downregulation of p53 controls hematopoietic stem cell self-renewal. Cell Cycle 9, 3297-3305 (2010). 